\title{
The Effect of Peers' and Teacher's E-Feedback on Writing Anxiety Level Through CMC Applications
}

\author{
https://doi.org/10.3991/ijet.v13i11.8448 \\ Mohamad Yahya Abdullah( $\left.{ }^{\varpi}\right)$ \\ Buraimi University College, Oman \\ Universiti Kebangsaan Malaysia \\ mabdullah@buc.edu.om \\ Supyan Hussin \\ Universiti Kebangsaan Malaysia \\ Mohanaad Shakir \\ Buraimi University College, Oman
}

\begin{abstract}
Computer Supported Collaborative Learning (CSCL) promotes learners to be more confident and self-directed in addition to enhancing their knowledge and general information throughout the peers' and teacher's electronic feedback (E-feedback). This study was carried out with 28 Master EFL/ESL students who registered in the elective course of Computer Application in ESOL. To examine the influence of peers' and teacher's electronic feedback on ESL writing anxiety level as well as their writing performance, Second Language Writing Anxiety Inventory (SLWAI) and semi-structured Interviews were employed. The major finding from the Paired T-Test which was performed on the pre-post of (SLWAI) revealed a significant difference between them $(p<.009)$ that reflected respondents' tendency to decrease their writing anxiety level after using peers' and teacher's e-feedback. Moreover, data collected from the interviews reported that the respondents perceived the e-feedback from peers and teacher as an important way to improve their writing performance.
\end{abstract}

Keywords-Computer Supported Collaborative Learning; CMC applications, Writing Anxiety; E-Feedback.

\section{Introduction}

Undeniably, the skill of writing is considered as one of most crucial English language skills due to its essential function within the educational, and workplace settings. There is a consensus among different scholars that writing in English as a second and foreign language context (ESL/EFL) is a complicated process which involves factors of social, cultural, motivational, and cognitive considerations[1]. Researchers of second language acquisition emphasize that students strive hard to pass this challenging course and they are aware of the fact that they need much training based on different strategies consol- 
idated with linguistic knowledge and the ability to express in the target language rhetorically [2][3]. Students, learning English composition in ESL/EFL context, face difficulties in many structural issues, especially when selecting words and phrases, formulating appropriate and correct grammatical structures, generating ideas and thoughts, and building ideas about a particular writing topic[4].

According to Santoso (2008), there is a set of limitations and problems which can be considered as authentic challenges to stifle ESL/EFL students to reach the skillful level of writing. They lack the ability to write in a grammatical and syntactical way and to express their views rhetorically in the target language which is because of the impact of the first language (L1) on the second language (L2)[3]. Besides, the influence of adopting the traditional and outdated teaching methods which extremely implemented the traditional drills and structured writing exercises. Moreover, the cultural influence which severely affects these challenges, preventing the EFL learners from reaching the highest level of writing skill; and subsequently, causes the anxiety about writing which most of the EFL learners are suffering from. These challenges may cause lack of selfconfidence and fear of criticism or fear of low evaluation among the EFL learners [5].

Over the last 30 years, a group of researchers has observed the anxiety during English writing process as one of the most hindering factors which impact on ESL/EFL learners' writing performance and might prevent them from performing well in the writing process[6][7][8][9]. Writing anxiety in ESL/EFL can be defined as a fear of writing process and students' prohibition from help, encouragement, and support while they are writing in addition to the difficulty they face with the writing task. ESL/EFL writing anxiety influences directly on the learners' motivation and academic achievement in addition to its effect on the practices inside the classroom [10].

Today's classroom is often found online or supplemented by online discussions and interactions where both students and instructors contribute to the learning outcomes. In a collaborative environment, the instructors pave the way for students to able to develop their understanding and construct their knowledge efficiently[11]. Mansor (2007:1) stated that students using computer-mediated applications "wrote more, asked more questions, used more language functions and adopted a more conversational tone in their language[12]. It enables the teacher to monitor the process of the students' writing to save class time". According to Resta and Laferrière (2007), Computer supported collaborative learning (CSCL) is considered as a set of groups' interactions in an educational system which has been achieved to facilitate the learning process through a communicative environment. The application of this system via computer-mediated communication tools can promote learners to be more confident and self-directed in addition to enhancing their knowledge and general information throughout the implementation of various tasks and activities[13].

Computer-mediated communication (CMC) as one of the telecommunication technologies represents the process of integrating computers and digital networks. It offers a large number of opportunities to provide more flexible learning programs so that it can be extensively used in the pedagogical practices [14]. Within CMC, there are no geographical boundaries so that "virtual online classrooms can draw on the global expertise and bring a multicultural perspective to any subject." Its incorporation into the world of education provides many facilities that lead to shifting teaching and learning 
process as a whole, especially, virtual learning environments. Furthermore, CMC smoothes the way to the individual education and enables teachers to interact with a group or on a one-to-one basis, which is most appropriate[15]. Its unique quality of time- and place-independent communication extensively gives the potential of online collaboration in diverse ways. Firstly, it allows for more "in-depth analysis and critical reflection, because the email can be answered more deliberatively than synchronous messages." Secondly, it permits learners to communicate with the teacher or with each other beyond the classroom [16].

Previous studies indicate that peers' and teacher's feedback can provide a real collaborative environment which in turn forms an authentic atmosphere of interaction between the students themselves from one side and their teacher from another side. It inspires them to give feedback to each other's writing, and subsequently; their writings will contribute to increasing their self-confidence and level of knowledge Atay and Kurt [9]. In spite of the fact that intensive researches have been performed to establish the significant results of this monolithic relationship, however, research has been done to examine the impact of this relationship on the anxiety sphere in the ESL/EFL writing. The current study investigates the effects of peers' and teacher's e-feedback via CMC applications (as parts of the technology area) upon the anxiety of the learners while they are engaging in the writing process. Learners can obtain beneficial results from the efficient use of their teachers' and peers' feedback through the use of their blogs and online discussion forums.

\section{Conceptual Framework}

Before discussing the effects of using peers' and teacher's e-feedback on students writing anxiety level, it is necessary to look at the conceptual framework of the study that guides the researcher to focus on specific constructs or variables to be studied. The framework, which is mainly based on certain principles that are drawn from the constructivist theory, and writing models, will also become the basis of this study. Fig. 1 illustrates the conceptual framework for this study.

Based on the conceptual framework of this study, the perspective of the socio-cultural approach towards language learning, based on Vygotsky's view, complements the situation which eases the direct relationship between the L2 learners and their social and cultural surroundings and conditions. In paper [17] researcher present again emphasized the significant role of 'collaborative learning approach' whereas the interaction between students and their teacher or among themselves is indispensable for creating a helpful situation that leads to their advancement through their own zone of proximal development. In other words, it indicates the gap between what the L2 learner could achieve alone and what he or she could achieve in co-operation with his or her peers who are more skillful or experienced.

Another view of the advancement of internet technology is held by Hussin (2011:8) who proposed that bigger zone of proximal development can be promoted during the learning process. He assumed that "learners might learn and /or acquire new knowledge and skills continuously; and subsequently, they might enjoy becoming autonomous 


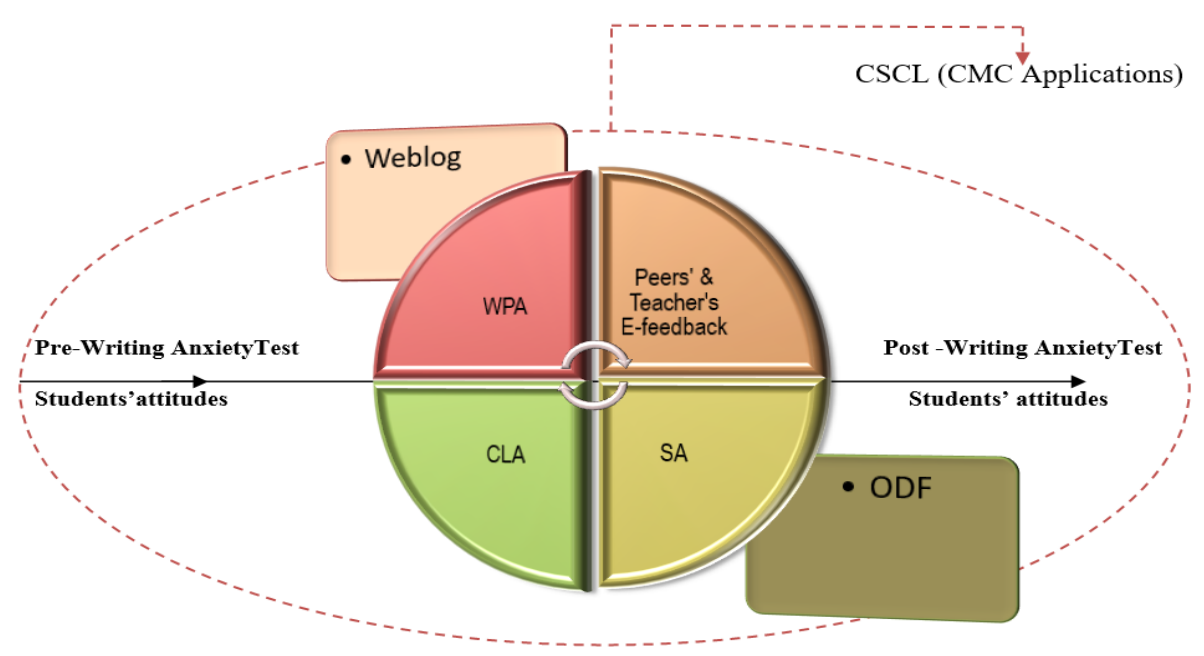

Fig. 1. Conceptual framework for this study

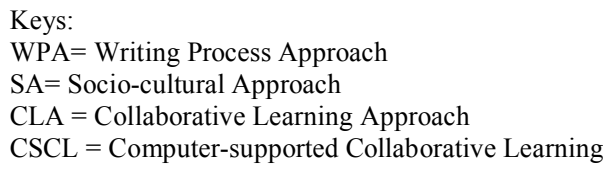

learners as thus, they could explore the possibility of enlarging and extending their learning and development zone[18]." He suggested that teachers should take their roles in paving the way for their learners seriously, to allow them being autonomous learners in their learning process. This might happen through creating a larger communication context by online discussion forums. In addition, the adoption of writing process approach as the teaching method will promote the students to be involved in several writing stages such as peer review and teacher feedback. In consequence, it is important to encompass all these views and principles to gain a helpful milieu which in turn can help the students to overcome their writing anxiety.

\section{Previous Studies}

Giving the crucial role of CSCL as an instructional method whereby students are encouraged to work together on the learning tasks has been asserted by several scholars [19][20][21]. Within this environment, learners engage the joint involvement of participants in a managed effort to solve their difficulties mutually. In the literature, it has been noted that the use of the technical applications could smooth the progress of collaborative learning such as the use of the applications of computer-mediated communication (CMC). The qualities of applying the technology could support student collaboration wherein the use of internet provides education with a diverse number of mediat- 
ing implementations which enhance the collaboration such as, blog, e-forum, conferencing systems, e-mail, and chat rooms. Michailidou and Econmides (2007:200) emphasized the importance of the diversity in CSCL. They claimed that "It is one thing to create diversity by recruiting learners - of different nationality, cultural background, race, gender, sexual orientation, religion, discipline, and another thing to develop a supportive educational environment in which individuals of diverse backgrounds can perform at their highest levels and contribute fully to the learning procedure[22]."

Central to the concept that writing is an information-sharing process; whereby learners can create their points of view depending on the others' observations. The quality of collaborative writing has the authentic occasions for the exchange of these ideas. According to Cicognani, synchronous and asynchronous activities promote students a potential interaction that boosts learners to refine their writing skills[23]. Kelley indicates that a lot of the development in technology relevant to pedagogical practices provides conciliating and helpful communication as well as broader access to information. This development paves the way to develop the ESL/ EFL writing proficiency[24].

Hrivela stated that employing the CMC tools in the pedagogical process provides students with a competent interaction via computers "networked environment through which they communicate with one another electronically in or outside the classroom." This may occur either in synchronous or asynchronous ways[25]. Moreover, Chang stated that asynchronous computer-mediated communication as a text-based program could be considered as a presentation medium which supports learners through an additional number of occasions to perform a practice of communication and interaction with one another[26]. Its quality of private community and the ability to use language learning strategies may enhance their self-confidence and desire, after which it will provide a good chance of developing their language competency[27].

In recent times, feedback has been considered as an essential factor for encouraging and reinforcing the learning process which in turn considerably contributes to improving students' writing skills[28]. This implication has apparently emerged in the domain of the L2 writing. In this paper, the authors present hypothesized that "Summative feedback, designed to evaluate writing as a product, has generally been replaced by formative feedback that points forward to the student's future writing and the development of his or her writing processes." As long as the feedback enhances the students' rhetorical choice as a part of the new academic literacy skill, it helps the L2 learners to acquire new knowledge and practices [29][30][31]. Warschauer[16], stated that CMC environment consolidated the student's role (student-centered) which led to strengthening the role of the students' participation through promoting the sense of group work and subsequently activated the concept of the students' interaction. Of course, in such an atmosphere, the feedback would be more enhancing and beneficial because "immediate feedback by instructors to correct the learners' errors played an important role in this faceless environment" [32].

In terms of exploring students' comments on their inclination towards their peers' feedback and to explore if the comments result in the revision of their drafts; Nguyen, conducted a study in Vietnam using 11 EFL students[33]. The respondents of this study used blogs as the tools of writing to write two topics and posted their comments on their peers' writings. The results of this study revealed that the feedback was effective in 
helping the students in refining their drafts, particularly while they are using the blogs as the tools of writing. Thus, this study gives the present researcher an authentic motivation to explore if the use of the peers' and teacher's feedback through blogging has any significant effect on the level of the writing anxiety.

\section{$4 \quad$ Methodology}

\subsection{Data Collection}

Purposive sampling technique was used to select respondents for the current study which consisted of 28 master ESL/EFL students who assigned at the course of Computer Application in ESOL. Data related to age shows that the majority (82\%) of the respondents are in the age range of the 23-27 years old. Besides, three instruments have been used to answer the research questions of the current study. Pre-post Tests from the ESL/EFL version of Cheng's (2004) Second Language Writing Anxiety Inventory (SLWAI) has been adopted to assess a combination of learners' attitudes, beliefs, and anxious feelings towards EFL writing. The semi-structured interview has been carried out in two stages. Each stage contained several themes which are related to all areas of the phenomenon under investigation. Finally, observation of documents has been used to observe the participants' behaviors by participating in their activities. The researcher immersed himself in the natural setting of the research and observed what students did in the real situation. Combining these three instruments to gather information allows the researcher of the study to triangulate the data for the sake of increasing credibility and validity of this study.

\subsection{Data Analysis}

The quantitative data were analyzed using the Statistical Package for Social Sciences (SPSS) version 21.0 software. In this stage, a descriptive analysis was used to compute students' levels of ESL/EFL writing anxiety before and after the use of peers' and teacher's e-feedback. Paired t-Test was used to examine the effect peers' and teacher's feedback on the level of ESL/EFL writing anxiety. The significance level was at 0.05 . The qualitative data were gathered from the interviews, and the observation of documents was connected and interrelated to the themes. These themes were categorized into sub-headings which are related to all areas of the phenomenon under investigation.

\subsection{Results}

\section{Quantitative data}

Students' Levels of Anxiety (Pre-Post). The Second Language Writing Anxiety Inventory (SLWAI) was distributed at the beginning and at the end of the study (pre-post tests), fig. 2 illustrates student's attitudes towards writing. 


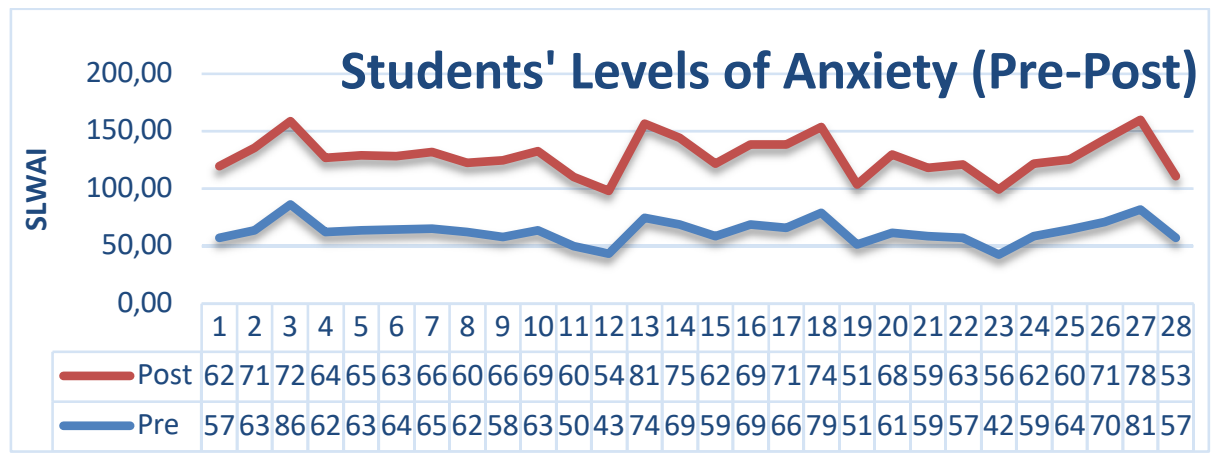

Fig. 2. Students' Levels of Anxiety (Pre-Post)

Fig. 3 shows the scores for students' levels of anxiety before and after using peers' and teacher's electronic feedback. The descriptive analysis revealed that the scores of 18 out of 28 respondents $(65 \%)$ have clear tendencies to decrease their writing anxiety after using peers' and teacher's e-feedback, 3 out of 28 respondents $(10 \%)$ remained in the same level of anxiety. Although 7 out of 28 respondents $(25 \%)$ demonstrated opposite results, their scores did not significantly change except those respondents $(\mathrm{N}=3)$ who demonstrated a significant change towards opposite results. However, the Paired T-Test which was performed on the pre-post total means revealed that a significant difference between them $(\mathrm{p}<.009)$, see figure 3 The Paired T-Test revealed that the respondents showed a tendency to decrease their writing anxiety level after using peers' and teacher's e-feedbacks, i.e., P-Value $=0.009$.

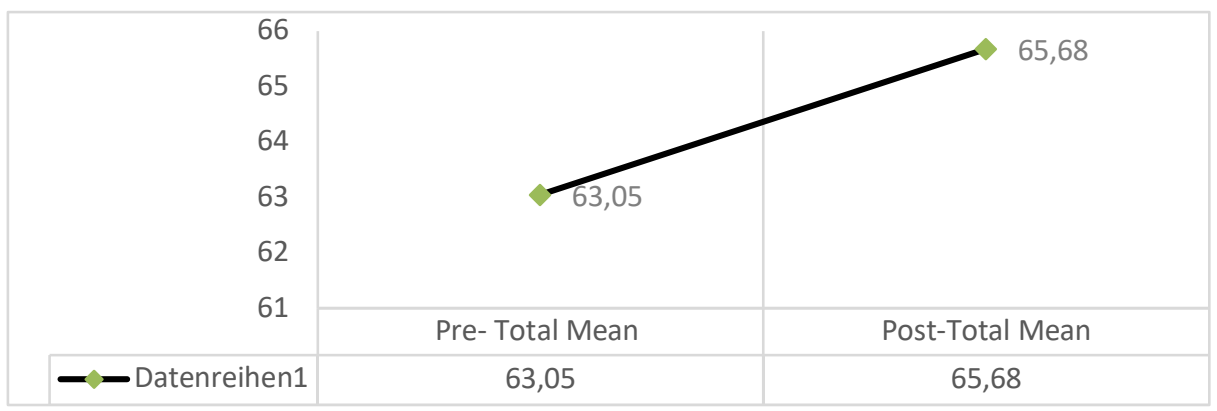

Fig. 3. Total Means for Pre and Post Tests

$* *=$ very significant

\section{Qualitative Data}

Peer Review. Peer review is considered as one of the most significant methods used in writing process approach (Hyland and Hyland, 2006). It has been observed that this helps immensely to indicate writers' mistakes. Writers have a good opportunity to find out their errors through their peer's review. Hence, this pedagogical technique method has been used through one of CMC tools, blog. The data shows that four respondents answered "yes" to the inquiry raised by the research if they prefer peer review. The data 
Paper-The Effect of Peers' and Teacher's E-Feedback on Writing Anxiety Level Through CMC Appli...

also revealed that they prefer $\mathrm{CMC}$ (blog) peer review than face-to-face learning mode. Respondent S 23 reported that:

"I prefer CMC (blog) .... Because the way we posted our paper without names made me avoid embarrassment. I don't like to face the person who reviews my paper because I might do a lot of mistakes." (Stage-2, S 23, L. 17, 19-21)

Regarding the role of peer's review in the improvement of writing performance, the data showed that peer review had helped students in their writing ability. Respondent S 22 said that:

"Because the feedback indicated to me the mistakes I did so it helped me to improve my writing ability." (Stage-2, S 22, L. 28-29)

Teacher feedback. Teacher feedback is one of the considerable writing process methods. It takes its role in improving writing ability for struggling writers. The use of teacher's feedback through CMC (blog) provided the respondents a new way to deal with this method. Interview data showed that the respondents reported comfortable attitudes towards teacher's feedback via CMC (blog); however, only one of the subjects preferred the traditional way of face to face feedback. In fact, applying the method of teacher's e-feedback has been admitted by the respondents of this research. This is shown in the following excerpts from the interview transcription:

S 6: "Because our teachers are more proficient and have more experiences so for sure their Feedback would be useful and beneficial for us." (Stage-2, S 6, L. 48-49)

S 23: "Well, I mean that my teacher is more proficient than me and his feedback would be more important to me. Emmm... You know I learned from him a lot." Stage2, $S$ 23, L. 43-44)

$\mathrm{S}$ 22: "Ifeel more comfortable with CMC Blog because it avoids me embarrassment and this Way of posting my paper are easier just like the peer review." (Stage-2, S 22, L. 45-46)

S 14: "I feel more comfortable with FTF." (Stage-2, S 14, L. 60)

\subsection{Discussion}

According to the analysis of qualitative and quantitative data, the results of this study revealed that According to the analysis of qualitative and quantitative data, the results of this study revealed that using the blog as one of the CMC tools promotes the respondents more comfortable and confident sensation. Its characteristics boost learners' motivation level and in turn, smooth the way to improve their outcomes. According to Warschauer (2002), CMC environment consolidated the student's role (student-centered) which led to strengthening the role of the students' participation through promoting the sense of group work and subsequently activated the concept of the students' interaction. Of course, in such an atmosphere, the feedback would be more enhancing and beneficial because "immediate feedback by instructors to correct the learners' errors played an essential role in this faceless environment" [34].Consequently, the re- 
spondents acknowledged that using the approach of writing process via CMC application, in particular, the use of teacher's and peer's e-feedback grants them the substantial opportunity to refine their writing performance. Cicognani (2000) indicated that synchronous and asynchronous tasks allow students to improve their writing process especially when they involve in discussion and problem-solving methods.

Furthermore, the findings of this study pointed out that the majority of 28 respondents demonstrated a tendency of decrease in their writing anxiety level over the use of peers' and teacher's e-feedback via CMC applications. In this sense, Atay and Kurt (2006) stated that a classroom based on a peer feedback application can provide a real collaborative environment. The results indicated that the use of peers' and teacher's efeedback had a positive effect on the students' attitudes toward writing which in turn contributed influentially in improving their writing ability. Writing process approach is considered as a problem-solving process. In contrast to product approach, process approach places much more emphasis on the "linguistic skills such as planning and drafting" than "linguistic knowledge, such as knowledge about grammar and text structure"[35]. Moreover, Siti Hamin (1998) sees that the aspects of writing process approach inspire learners to enhance their writing competency. Its features of teacher and peer feedback, group work interaction promote knowledge construction and problemsolving ability.

Hence, the respondents of this study showed positive attitudes towards group work interaction, and they declared that they have a high tendency to keep working collaboratively with their peers, mainly doing peer-reviews and mentoring their peers' assignments. They stated that the stage of editing helps them to evolve the writing performance. Finally, the finding of peers' and teacher's e-feedback recoded positive attitudes. The respondents of this study stated that they prefer this kind of feedback rather than face to face one. They emphasized its vital role in their writing development. According to Ferris and Robert[36], "students who received feedback significantly outperformed students who received no feedback.

\section{Conclusion}

From the results of the study, it is undeniable that the use of writing process methods within CMC environment provides authentic opportunities for the students to interact with their teacher and peers to get much better benefits than the traditional ways of teaching. This group interaction was implemented through the class blog and e-forum. The findings of the study asserted that in addition to the 'time- and place-independent communication' quality of CMC environment, the group interaction within this environment facilitated the process of acquiring world knowledge and knowledge of the language. Moreover, the quality of collaborative writing represented by peers' and teacher's electronic feedback has given them excellent opportunities for the exchange of their ideas. Besides that, its quality of private community and the ability to use language learning strategies which enhanced their self-confidence and desire represented an excellent opportunity of developing their language competency. 
Accordingly, all these qualities contributed practically in reducing their level of writing anxiety. What we have is a much more flexible tool which can meaningfully enhance the learning experience. EFL students could find the real occasion to practice their language through the use of $\mathrm{CMC}$ applications. Furthermore, the use of the process approach as a method of teaching will improve their writing outcomes. Therefore, the researcher suggests that attention should be given to both CMC applications and writing process approach in the writing classroom. Moreover, students should be given the opportunity to write drafts and discuss them with their peers as well as teachers. Students should also have the chance to write the final draft before submitting the paper to the teacher to be graded.

Moreover, the results of this study revealed that social interaction such as group discussion plays a key role in reducing the students' anxiety while they engage in the writing process, principally within CMC environment. Therefore, it is suggested that the interactive composition activities, such as writing some papers collaboratively should be encouraged. Herein, students may gain confidence when they realize that their peers also have challenges in writing so that they may feel less anxious while they are writing.

Finally, the researchers of this study recommend carry out other studies to investigate the effects of using different applications of CMC such as the use of Chatrooms, Bulletin Boards, and Electronic Dialogue Journals. The researchers also recommend studying how factors such as gender, ethnic, linguistic, and cultural differences could affect students' attitudes towards writing pre and post using CMC application.

\section{References}

[1] S. Raoofi, S. H. Chan, J. Mukundan, and S. M. Rashid, "A qualitative study into L2 writing strategies of university students," English Lang. Teach., vol. 7, no. 11, p. 39, 2014. https://doi.org/10.5539/elt.v7n11p39

[2] S. Lee, "Facilitating and inhibiting factors in English as a foreign language writing performance: A model testing with structural equation modeling," Lang. Learn., vol. 55, no. 2, pp. 335-374, 2005. https://doi.org/10.1111/j.0023-8333.2005.00306.x

[3] A. Santoso, "Scaffolding an EFL (English as a foreign language) effective writing class in a hybrid learning community," Queensland University of Technology, 2010.

[4] N. A. Shukri, "Second Language Writing and Culture: Issues and Challenges from the Saudi Learners' Perspective.," Arab World English J., vol. 5, no. 3, 2014.

[5] M. M. Abdel Latif, "Sources of L2 writing apprehension: a study of Egyptian university students," J. Res. Read., vol. 38, no. 2, pp. 194-212, 2015. https://doi.org/10.1111/j.14679817.2012.01549.x

[6] L. L. Reeves, "Minimizing writing apprehension in the learner-centered classroom," English J., vol. 86, no. 6, pp. 38-45, 1997. https://doi.org/10.2307/820367

[7] Y. Cheng, "Factors associated with foreign language writing anxiety," Foreign Lang. Ann., vol. 35, no. 6, pp. 647-656, 2002. https://doi.org/10.1111/j.1944-9720.2002.tb01903.x

[8] L. Fu-lan, "Using Computer-mediated-communication to Overcome the Anxiety in ESL Writing," US-China Foreign Lang., vol. 4, no. 11, pp. 97-101, 2006.

[9] D. Atay and G. Kurt, "Prospective teachers and L2 writing anxiety," Asian EFL J., vol. 8, no. 4, pp. 100-118, 2006. 
Paper-The Effect of Peers' and Teacher's E-Feedback on Writing Anxiety Level Through CMC Appli...

[10] M. Y. Abdullah, "An investigation on the effects of CMC applications on ESL/EFL writing anxiety among postgraduate students at UKM," Unpubl. MA thesis, Univ. Kebangs. Malaysia, Bangi, Malaysia, 2011.

[11] O. Olivares, "Collaborative vs Cooperative Learning: The Instructor's Role in Computer Supported Collaborative Learning," ORVIS, K. LASSITER, A.(coords.) Comput. Collab. Learn. Best Pr. tices Princ. Instr., p. 20, 2008. https://doi.org/10.4018/978-1-59904-753$\underline{9 . \operatorname{ch} 002}$

[12] N. Mansor, "Collaborative learning via email discussion: strategies for ESL writing classroom," Internet TESL J., vol. 13, no. 3, 2007.

[13] P. Resta and T. Laferrière, "Technology in support of collaborative learning," Educ. Psychol. Rev., vol. 19, no. 1, pp. 65-83, 2007. https://doi.org/10.1007/s10648-007-9042-7

[14] R. K. L. Ko, P. Jagadpramana, M. Mowbray, S. Pearson, M. Kirchberg, Q. Liang, and B. S. Lee, "TrustCloud: A framework for accountability and trust in cloud computing," in Services (SERVICES), 2011 IEEE World Congress on, 2011, pp. 584-588. https://doi.org/10.1109/SERVICES.2011.91

[15] S. Naidu, Learning \& teaching with technology: Principles and practices. Psychology Press, 2003. https://doi.org/10.4324/9780203416891

[16] M. Warschauer, "Networking into academic discourse," J. English Acad. Purp., vol. 1, no. 1, pp. 45-58, 2002. https://doi.org/10.1016/S1475-1585(02)00005-X

[17] K. Suh, P. K. Couchman, J. Park, H. Hasan, and others, "The application of activity theory to Web-mediated communication," Inf. Syst. Act. theory, vol. 3, pp. 122-140, 2003.

[18] S. Hussin, "Creating a bigger ZPD for ESL learners via online forum in Malaysia," Coll. Teach. Methods Styles J., vol. 4, no. 11, pp. 1-10, 2008.

[19] E. Lehtinen, K. Hakkarainen, L. Lipponen, M. Rahikainen, and H. Muukkonen, "Computer supported collaborative learning: A review," JHGI Giesbers reports Educ., vol. 10, p. 1999, 1999.

[20] K. L. Orvis and A. L. R. Lassiter, "Computer-Supported Collaborative Learning," Teach. Learn. with virtual teams, p. 158, 2005.

[21] C. O'Malley, Computer supported collaborative learning, vol. 128. Springer Science \& Business Media, 2012.

[22] A. Michailidou and A. Economides, "Gender and diversity in collaborative virtual teams," Comput. Support. Collab. Learn. Best Pract. Princ. Instr., pp. 199-224, 2008. https://doi.org/10.4018/978-1-59904-753-9.ch010

[23] A. Cicognani and others, "Concept mapping as a collaborative tool for enhanced online learning," Educ. Technol. Soc., vol. 3, no. 3, pp. 150-158, 2000.

[24] M. J. Kelley, The impact of weblogs on the affective states and academic writings of L2 undergraduates. University of Virginia, 2008.

[25] A. Hirvela, "Computer-mediated communication in ESL teacher education," ELT J., vol. 60, no. 3, pp. 233-241, 2006. https://doi.org/10.1093/elt/ccl003

[26] Y. Y. Chang, "The potential of synchronous text-based computer-mediated communication for second language acquisition," Issues Inf. Syst., vol. 8, no. 2, pp. 355-361, 2007.

[27] S. Hussin, M. Y. Abdullah, N. Ismail, and S. K. Yoke, "The Effects of CMC Applications on ESL Writing Anxiety among Postgraduate Students," English Lang. Teach., vol. 8, no. 9, p. 167, 2015. https://doi.org/10.5539/elt.v8n9p167

[28] K. Hyland and F. Hyland, "Feedback on second language students' writing," Lang. Teach., vol. 39, no. 2, pp. 83-101, 2006. https://doi.org/10.1017/S0261444806003399

[29] K. Hyland, "Disciplinary interactions: Metadiscourse in L2 postgraduate writing," J. Second Lang. Writ., vol. 13, no. 2, pp. 133-151, 2004. https://doi.org/10.1016/i.jslw.2004.02.001 
Paper-The Effect of Peers' and Teacher's E-Feedback on Writing Anxiety Level Through CMC Appli...

[30] S. Matsumura and G. Hann, "Computer anxiety and students' preferred feedback methods in EFL writing," Mod. Lang. J., vol. 88, no. 3, pp. 403-415, 2004. https://doi.org/10.1111/ j.0026-7902.2004.00237.x

[31] D. Isa, L. L. Hong, V. P. Kallimani, and R. Rajkumar, "Text Document pre-processing using the Bayes formula for classification based on the vector space model," Comput. Inf. Sci., vol. 1, no. 4, p. 79, 2008. https://doi.org/10.5539/cis.v1n4p79

[32] P. Krish, T. Vikneswaran, and S. Hussin, "Exploiting Blogs in the ESL Classroom.," Pertanika J. Soc. Sci. Humanit., vol. 22, 2014.

[33] P. T. T. Nguyen, "Peer feedback on second language writing through blogs: The Case of a Vietnamese EFL classroom," Int. J. Comput. Lang. Learn. Teach., vol. 2, no. 1, pp. 13-23, 2012. https://doi.org/10.4018/ijcallt.2012010102

[34] N. C. Musa, K. Y. Lie, and H. Azman, "Exploring English language learning and teaching

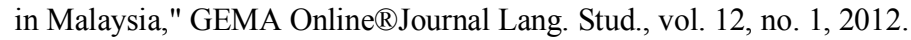

[35] R. Badger and G. White, "A process genre approach to teaching writing," ELT J., vol. 54, no. 2, pp. 153-160, 2000. https://doi.org/10.1093/elt/54.2.153

[36] S. J. Jones, "Blogging and ESL writing: A case study of how students responded to the use of weblogs as a pedagogical tool for the writing process approach in a community college ESL writing class," The University of Texas at Austin, 2007.

\section{$7 \quad$ Authors}

Mohamad Yahya Abdullah is with the Buraimi University College, Oman and the Faculty of Social Sciences and Humanities, Universiti Kebangsaan Malaysia (e-mail: mabdullah@buc.edu.om).

Supyan Hussin is with Faculty of Social Sciences and Humanities, Universiti Kebangsaan Malaysia.

Mohanaad Shakir is with the Buraimi University College, Oman

Article submitted 16 February 2018. Resubmitted 16 May, 29 April, and 07 August 2018. Final acceptance 09 August 2018. Final version published as submitted by the author.s 